Macedonian Pharmaceutical Bulletin, 66 (Suppl 1) 171 - 172 (2020)

Online ISSN $1857-8969$

UDC: 615.454.1-074:543.544.5.068.7]:617.7-085.281.8

DOI: 10.33320/maced.pharm.bull.2020.66.03.085

Short communication

\title{
Quality-by-design based development of a stability indicating method for antiviral ophthalmic ointment
}

\author{
Emilija Arsovska Popovska*, Filip Gogu, Nina Peneva, Frosina Jovanovic, \\ Eleonora Trajanovska, Suzan Memed Sejfulah, Ana Atanasova, Packa Antovska, \\ Sonja Ugarkovic
}

\begin{abstract}
Institute for Research and Development, Alkaloid AD-Skopje, Blvd. Aleksandar Makedonski 12, 1000 Skopje, North Macedonia
\end{abstract}

\section{Introduction}

Some ocular pathologies such as herpes simplex, virus retinitis and acute retinal necrosis are usually treated by administering antiviral drug product. Antiviral eye ointment is a sterile preparation, manufacturing by incorporation of very finely powdered antiviral active substance into a petrolatum base. The base is designed to have melting point close to human body temperature and can be used as anhydrous medium for the delivery of moisture-sensitive drugs.

Several methods have been reported for the determination of this active component in pharmaceutical formulations, based on different analytical techniques. HPLC method for the assay of active compounds is superior to other conventional methods in speed, precision, specificity and ease of performance.

The aim of our work was to develop rapid HPLC assay method for determination of antiviral active compound by implementation of $\mathrm{QbD}$ principles. Quality by design approach in method development help to better understand chromatographic variables in less time compared to traditional, one factor at a time method development (Gayakwad et al., 2015; Karmarkar et al., 2011).

\footnotetext{
* earsovska@alkaloid.com.mk
}

\section{Materials and methods}

All the chemicals and reagents used in this study were of analytical grade with high percentage purity. Active substance standard, analytical reference standards and related impurities were supplied from EDQM.

Working solutions of drug product were prepared according to in-house method, in concentration $0.025 \mathrm{mg} / \mathrm{mL}$. According the method, eye ointment should be suspended in nonpolar organic solvent at $60{ }^{\circ} \mathrm{C}$, and target compound isolated by extraction with aqueous solvent.

The development and optimization were performed on Agilent 1290 Infinity HPLC system supplied with binary pump connected to a 12position solvent selection valve and two thermostated column compartments with 8-position valves allowing eight columns to be coupled at the same time. Chromeleon Console chromatographic software was used to control the instrument, compile data and process the same.

Statistical experimental design, data processing, modelling and optimization of the analytical method were accomplished using Fusion AE (version 9.7.1 SR2c, S-Matrix Corporation, Eureka, CA), which is QbD based software for analytical method development that integrates method robustness testing into method development. Fusion method 
development is two phase strategy; composed of screening and optimization phase. Screening experiments examine the critical chromatographic selectivity factors, including column type, $\mathrm{pH}$ and mobile phase composition. Method optimization phase use the results from screening phase plus additional variables with tighter ranges to determine the optimum chromatographic conditions.

In the screening phase following conditions were tested: ten different columns with $\mathrm{C} 18$ chemistry of stationary phase: Inertsil ODS-3V 250$4.6 \mathrm{~mm}(5 \mu \mathrm{m})$, ACE $5 \mathrm{C}-18250-4.0 \mathrm{~mm}(5 \mu \mathrm{m})$, Zorbax Eclipse Plus C18 250x4.6 (5 $\mu \mathrm{m})$, XBridge C18 150-4.6 mm (5 $\mu \mathrm{m})$, X-Terra RP18 150-4.6 mm $(5 \mu \mathrm{m})$, SunFire C18; 150-4.6 mm $(3.5 \mu \mathrm{m})$, BDS Hypersil 150-4.6 mm (5 $\mu \mathrm{m})$, Inertsil ODS-3V 150$4.6 \mathrm{~mm}(5 \mu \mathrm{m})$, BDS Hypersil 100-4.6 (3 $\mu \mathrm{m})$, ODS Hypersil 100-4.6 mm $(3 \mu \mathrm{m})$; two types of organic solvents: methanol and acetonitrile, three different buffer types containing TEA, $\mathrm{CH}_{3} \mathrm{COONH}_{2}$ or $\mathrm{KH}_{2} \mathrm{PO}_{4}$ and different range of $\mathrm{pH}$ of the buffer: $\mathrm{pH} 2.5, \mathrm{pH} 4.5$ and $\mathrm{pH}$ 6.5. Flow rate was tested in range $0.8 \mathrm{~mL} / \mathrm{min}-1.5 \mathrm{~mL} / \mathrm{min}$, in isocratic mode. Injection volume was $10 \mu \mathrm{L}$. UV detection was performed at $254 \mathrm{~nm}$.

\section{Results and discussion}

According to obtained results, analyzed with Pareto diagram and graphical reports, two key parameters have main influence on chromatography, type of column and type of organic modifier, while other experimental variables, type of buffer, $\mathrm{pH}$ and flow rate have minimal effect.

Due to hydrophilic nature of the active component, retention characteristics of the solute are affected by minimal volume percent of organic modifier in mobile phase. When acetonitrile is used as organic modifier in the mobile phase, active compound has very little retention on all columns tested. The retention of components was significantly better by using methanol as organic modifier. Since our purpose is to develop robust and reproducible method with reasonable percent of organic modifier, methanol was chosen as organic solvent in mobile phase for next stages of method optimization.

Inertsil ODS-3V 250-4.6 mm $(5 \mu \mathrm{m})$ column provides broad range of combinations of screening conditions (percent of organic solvent and flow rate) at which the specified criteria meet the set goals, hence it is selected for next method optimization step. In method optimization phase finer variations of experiment conditions were tested: narrower range of $\mathrm{pH}(\mathrm{pH} 2.3-\mathrm{pH} 3.2)$, proportion of methanol (10\%-20\%) in mobile phase, flow rate $(0.8 \mathrm{~mL} / \mathrm{min}$ to $1.5 \mathrm{~mL} / \mathrm{min})$ and column temperature $\left(25^{\circ} \mathrm{C}-40^{\circ} \mathrm{C}\right)$.

Final conditions for the analytical method were chosen by application of Fusion method development overlay graph, which predicts the ranges of chromatographic parameters that generate robust method. After confirming optimized method for quantitative determination of active compound in the presence of its impurities and degradation products, specificity, linearity, accuracy, robustness and precision were confirmed with method validation as per ICH guidelines.

\section{Conclusion}

Comprehensive analytical method for quantification of antiviral drug product was developed by application of automated QbD method development approach using Fusion AE software. Multivariate analysis of several critical method parameters including column and solvent type, mobile phase composition, $\mathrm{pH}$, column temperature and flow rate were used to determine the best performing analytical procedure. A robust final method was obtained with a column temperature of $25{ }^{\circ} \mathrm{C}$, percent strong solvent of $15 \% \pm 2 \%$, and $\mathrm{pH}$ 2.5 \pm 0.2 . QbD principle to method development and optimization has enabled to better understand the method variables, leading to less chance of failure during method application. The implementation of QbD Fusion AE approach has provided a better performing and more robust method in less time compared to manual method development.

\section{References}

Gayakwad, A., Kanwale, N., Mali, K., Bhalerao, K., Yadav, S., 2015. Quality by design: A new approach to analytical method development. World J. Pharmacecutical Res. 4, 586-601.

Karmarkar, S., Garber, R., Genchanok, Y., George, S., Yang, X.H.R., 2011. Quality by Design (QbD) based development of a stability indicating HPLC method for drug and impurities. J. Chromatogr. Sci. 49, 439446.

Maced. Pharm. Bull. 66 (Suppl 1) 171 - 172 (2020) 